\title{
Features of Plasma Electrolytic Formation of Manganese- and Cobalt-Containing Composites on Aluminum Alloys
}

\author{
Ann V. Karakurkchi (D), ${ }^{1}$ Nykolay D. Sakhnenko (D), ${ }^{1}$ Maryna V. Ved' ${ }^{(D},{ }^{1}$ Ihor S. Luhovskyi, \\ Hryhoriy A. Drobakha, ${ }^{2}$ and Maryna V. Mayba ${ }^{1}$ \\ ${ }^{1}$ National Technical University "Kharkiv Polytechnical Institute", Kyrpychova Str. 2, Kharkiv 61002, Ukraine \\ ${ }^{2}$ National Academy of the National Guard of Ukraine, Maidan Zakhysnykiv Ukrainy, 3, Kharkiv 61001, Ukraine \\ Correspondence should be addressed to Ann V. Karakurkchi; anyutikukr@gmail.com
}

Received 3 May 2019; Revised 17 July 2019; Accepted 24 July 2019; Published 7 August 2019

Academic Editor: Saliha Ilican

Copyright (c) 2019 Ann V. Karakurkchi et al. This is an open access article distributed under the Creative Commons Attribution License, which permits unrestricted use, distribution, and reproduction in any medium, provided the original work is properly cited.

\begin{abstract}
This paper presents the results of studies on the electrochemical treatment characteristics of aluminum and alloys in alkaline electrolytes. It is shown that the heterogeneity of the alloys composition complicates the formation of the surface oxide layer. To homogenize the treated surface and obtain oxide coatings doped with manganese and cobalt, electrolytes based on $\mathrm{KOH}$ and $\mathrm{K}_{4} \mathrm{P}_{2} \mathrm{O}_{7}$ with the addition of $\mathrm{KMnO}_{4}$ and $\mathrm{CoSO}_{4}$ were used. Plasma electrolytic oxidizing (PEO) in these electrolytes in the range of current densities 5-20 A/ $\mathrm{dm}^{2}$ allows to obtain mixed oxide coatings which contained both aluminum oxide matrix and doping metal oxides $\mathrm{Al}_{2} \mathrm{O}_{3} \cdot \mathrm{MnO}_{\mathrm{x}}$ and $\mathrm{Al}_{2} \mathrm{O}_{3} \cdot \mathrm{CoO}_{\mathrm{y}}$. It is shown that an increase in the PEO current density and the concentration of manganate- and cobalt(II) ions in the solution leads to an increase the content of dopant metals in the coatings outer layer. The incorporation of manganese and cobalt oxides in the composition of the surface layers was confirmed by the results of X-ray structural analysis. The rational modes of aluminum alloys PEO treatment were substantiated to obtain coatings with manganese and cobalt contents up to 25-40 at.\%. Formed oxide systems have a developed surface and high adhesion to the base metal and show an increased corrosion resistance and catalytic activity. This allows us to view them as promising materials for air-and watercleaning technologies and internal combustion engine waste gas purification systems.
\end{abstract}

\section{Introduction}

An efficient development of science-intensive and raw material-intensive industry branches including the development of sophisticated, more accurate, and reliable multipurpose technological devices and their elements conditions a wide application of functional coatings and stiffens the requirements set to them. An innovative solution for this problem can be the use of new science-intensive technologies and technology research areas that combine the methods of controlled changes in physical and chemical properties of the surface layers of structural materials. It enables the formation of the coatings with prescribed properties directly on the work material getting the performances that considerably improve base metal indices [1]. Hence, we can assert that the development of innovative ecologically friendly technologies used for the application of highly efficient and reliable coatings onto metal substrates is considered today to be one of the most topical real-life problems.

An extensive use of aluminum and its alloys as the stateof-the-art structural materials and the carriers for the active systems of a different purpose is conditioned by a set of physical, mechanical, and chemical properties. Aluminum alloyed with magnesium, manganese, iron, silicon, copper, and other components has an increased strength and hardness and acquires appropriate heat resistance and other properties. Undesirable changes are also observed, in particular, the electrical conductivity is decreased inevitably; the corrosion resistance is degraded in many cases in corrosive media, and a relative density is increased. The reason for this is a heterogeneous structure and surface of the materials due to the formation of intermetallic compounds of alloying components with the base metal and admixtures [2]. In its 
turn, it complicates the process of the surface treatment of aluminum alloys, especially in the case of thick coatings.

The formation of functional oxide coatings or oxide layers on the aluminum alloys doped with transition metal compounds is typically carried out by means of impregnation of porous substrates or finely dispersed substrates with appropriate solutions followed by their thermal decomposition [3, 4]. However, in this case, we fail to get a strong adhesion of an active layer to the carrier. Therefore, the engineering solutions that enable the combination of the surface treatment and the coating formation on the treated metal surface in one process are of great interest. Such an approach provides a high adhesion and uniform distribution of doping components on the surface.

Lately, plasma processing methods have been increasingly used for this purpose, especially in the electrolytes. Electrochemical processing of the material surface in high-energy modes is called as the plasma electrolytic oxidizing (PEO) that is also called as the anode-spark or microarc oxidizing $[5,6]$. This method of the surface modification has advantages such as availability of an easyto-operate technological equipment and nontoxic working electrolytes, optionality of the stage of preliminary preparation of the surface of parts, and a possibility of the efficient treatment of large-size and figurine-shaped items. These peculiarities characterize the process of PEO treatment as cost efficient, ecologically friendly, and resource-saving.

Investigating the processes of aluminum alloys' surface directional modification by formation PEO coatings is a promising practical task.

\section{Features of PEO Treatment Aluminum and Its Alloys}

The physical-\&-mechanical and physical-\&-chemical properties of aluminum alloys depend significantly on the composition and ratio of basic and alloying components. The intermetallic compounds of a different composition (Table 1) that are contained in aluminum alloys as strengthening phases not only change alloy properties, but also affect the surface treatment process, in particular, the formation of conversion coatings and other surface layers.

The presence of given compounds in the surface layer of the material results in a change of its electrochemical properties. This fact should be considered when substantiating the composition of electrolyte solutions and developing the PEO technological modes.

Electrochemical technologies are widely employed for the modification of surfaces of metals and alloys by forming coatings with different compositions and purposes $[4,9,10]$.

$\mathrm{PEO}$ of valve metals is traditionally carried out in homogeneous electrolytes, which are characterized by high stability and ease of adjustment during operation. Such solutions make it possible to change qualitative and quantitative composition of surface layers in a wide range [6]. Moreover, these electrolytes allow efficient treatment of alloys with different chemical composition and formation of oxide coatings doped with one or more components $[5,11]$. Electrolyte suspensions consisting of a main homogeneous
TABLE 1: Intermetallic compounds in aluminum alloys $[7,8]$.

\begin{tabular}{|c|c|}
\hline Alloy (ISO) & Intermetallic compounds \\
\hline A2024 & $\begin{array}{l}\text { Hardening phases } \theta\left(\mathrm{Al}_{2} \mathrm{Cu}\right) \text { i } \mathrm{S}\left(\mathrm{Al}_{2} \mathrm{CuMg}\right) \\
\text { intermetallic compounds }(\mathrm{Fe}, \mathrm{Mn})\end{array}$ \\
\hline A3003 & $\begin{array}{c}\mathrm{MnAl}_{6} \text {, in } \mathrm{Fe} \text { and Si presence- }-\mathrm{Al}_{6}(\mathrm{Fe}, \mathrm{Mn}), \alpha \\
\text { (AlFeSi), and AlFeSiMn }\end{array}$ \\
\hline AlSi12CuNiMg & $\begin{array}{c}\beta-\mathrm{FeSiAl} l_{5},(\mathrm{FeMn})_{3} \mathrm{Si}_{2} \mathrm{Al}_{15}, \mathrm{FeNiAl}_{9}, \theta-\mathrm{CuAl}_{2}, \\
(\mathrm{CuNi})_{2} \mathrm{Al}_{3}, \mathrm{CuNiAl}{ }_{6}, \mathrm{Mg}_{2} \mathrm{Si}, \mathrm{W}-\mathrm{CuSi}_{4} \mathrm{Mg}_{5} \mathrm{Al}_{4}, \\
\pi-\mathrm{FeMg}_{3} \mathrm{Si}_{6} \mathrm{Al}_{8}\end{array}$ \\
\hline
\end{tabular}

electrolyte and additives from powders with varying nature and dispersion degree are also used $[12,13]$. In this case, besides the electrochemical and thermochemical reactions, the growth of the coating occurs due to the mechanical introduction of particles from the working solution.

It should be noted that the type of the electrolyte used and the nature of doping components predetermine the composition and properties of the formed oxide layer.

In [14], PEO samples of an Al-Si alloy are treated in alkaline silicate electrolyte. The authors found that, in the oxidizing process, the glow of discharges occurs predominantly at the boundaries of $\mathrm{Si}$ inclusions. As a result, the formation of a coating over all sample surfaces is inhibited, and the formed oxide layer is uneven. The surface morphology is characterized by the presence of large dendrites of silicon oxide. To obtain uniform oxide coatings, authors recommend to process the alloy samples at least 60 minutes.

Similar patterns were revealed by the authors of [15] when studying the PEO process of an aluminum alloy in a silicate electrolyte with sodium phosphate additives. It has been established that silicon particles in the composition of the alloy and eutectic Si phases inhibit the oxidation of aluminum and affect the composition and morphology of the resulting coatings.

It should be noted that $\mathrm{PEO}$ coatings formed at $\mathrm{Al}$ alloys in silicate electrolytes have increased microhardness and corrosion resistance in comparison with the untreated surface $[16,17]$. However, through a significant content of $\mathrm{Si}$ in the surface layers, these parameters are not optimal.

To expand the spectrum of functional properties of PEO coatings on aluminum alloys, it is advisable to use complex electrolytes and introduce additional components into the coating composition. In particular, the incorporation of transition metal oxides makes it possible to obtain catalytically active coatings on aluminum alloys $[4,18]$.

The author of [11] used aluminum silicate electrolytes with additions of sodium tetraborate, trilon B, acetic acid, and transition metal acetates to obtain oxide coatings on aluminum alloy A1050. The coatings were formed by alternating current at an average density of $100 \mathrm{~mA} / \mathrm{cm}^{2}$. Under these conditions, uniform oxide layers with a dopant content of 1.11-5.43 at.\% were obtained. At the same time, the coatings contain $8.46-13.5$ at. $\%$ of Si and 8.06-32.62 at.\% of carbon, which is explained by the thermolysis of the electrolyte components with PEO.

In [19] doped with magnesium, manganese and zinc oxide coatings for the alloy AD1 were formed from polyphosphate electrolytes. It is established that the content of 
the admissible elements in the coating is proportional to the concentration ratio of polyphosphates and the metal salt in the solution. The phase composition of the oxide layers varies with the time of the PEO and the composition of the working solution.

Polyphosphate electrolytes were also used to produce oxide coatings on an aluminum alloy AMnM with a high content of dopant [20]. It is shown that the formation of polyphosphate complexes with doping metals promotes their uniform incorporation into oxide films.

Also, it should be noted that, from traditional sulfate electrolytes, it is impossible to obtain oxide coatings with a thickness of more than $30-40 \mu \mathrm{m}$ on the A2024 alloy due to the high copper content $[21,22]$.

Thus, for effective treatment of the aluminum surface, it is advisable to use electrolytes containing ligands, in particular pyrophosphates. At the initial stages of oxidizing, the alloying components form soluble pyrophosphate complexes, which ensures the homogenization of the aluminum surface layer composition. Thereby, barrier alumina is formed on the surface and conditions are created for implementing the process in the microarc mode. As a result, an oxide coating uniformly distributed over the surface is formed and the transition metals additives incorporation is ensured.

Hence, we can conclude that it is reasonable to perform the PEO of the alloys of a complicated structure in alkaline electrolytes with the addition of pyrophosphate ligands. During oxidizing, it allows us to homogenize the alloy surface by decreasing the content of alloying components. This creates conditions for the formation of uniform aluminum phase oxide film, following by passing the oxidizing process in the microarc mode which allows the incorporation of dopants in thick oxide coatings [23].

So, the transition, precious, rare and scattered metals and some nonmetals can be added to the composition of surface oxide layers using the PEO method [18, 24-26]. The nature of dopants will predictably affect the functional properties of obtained oxide layers [27]. The selection of manganese and cobalt as doping components for oxide coatings is conditioned by their high-catalytic properties in the neutralization reactions of toxic components $[18,28]$. In this case, the composition of the electrode active particles in the electrolyte, which are involved in electrochemical and chemical reactions during PEO, is important. For example, the cations of polyvalent metals are capable of direct oxidizing, forming the cations or oxo-compounds with a higher oxidation state. The last participate in subsequent thermochemical transformations. Nonmetal oxyanions (for example, $\mathrm{SiO}_{3}{ }^{2-}, \mathrm{P}_{2} \mathrm{O}_{7}{ }^{4-}$ ), are not oxidized but show the tendency to the deoxygenation and dehydration especially at high temperatures. Some oxymetalates $\left(\mathrm{MnO}_{4}{ }^{-}, \mathrm{Cr}_{2} \mathrm{O}_{7}{ }^{2-}\right)$ show the tendency to the intramolecular redox reactions.

We assumed that the PEO of aluminum alloys in the presence of oxyanions and/or the cations of a different nature create conditions for the electrochemical and thermochemical reactions that result in the formation of mixed oxide coatings with a high adhesion to the substrate.
The two types of electrolytes were used to study the PEO processes of aluminum alloys, and the dopant metals were added to them. The first type of electrolytes is based on potassium hydroxide, and the second type of electrolytes is based on potassium pyrophosphate. To dope oxide coatings with manganese, potassium manganate(VII) was added to the electrolytes of the first type. Such an approach is explained by the data obtained during the research [29] that allow us to conclude that it is impossible to get oxide coatings with a large content of manganese oxides from the solutions with the addition of $\mathrm{Mn}$ (II) salts. It is suggested to incorporate cobalt from pyrophosphate electrolytes with the addition of $\mathrm{CoSO}_{4}$, similar to the oxidizing of titanium alloys [23].

It should be noted that all the basic mechanisms of a classic PEO are inherent in the formation process of coatings on aluminum alloys in specified solutions. Proceeding from the available concepts of the PEO mechanism in high-energy fields, we can mark out the four stages of the formation process of oxide coatings [5]:

(i) The first stage (I) is the formation of primary (phase) oxide film following the electrochemical mechanism prior to the electric discharge ignition

(ii) The second stage (II) is the breakdown of oxide film and the formation of plasma bunch in the discharge channel (luminescence and scintillation)

(iii) The third stage (III) is gas-phase and thermochemical reactions with the participation of metal and electrolyte (ignition of microarc discharges)

(iv) The fourth stage (IV) is the condensation and polyamorphous conversions of oxide phases (the microarc-to-arc discharge transition)

In this case, the chronograms of forming voltage have a classic view with the separation into specific regions, in particular, the prespark (I) and spark (II) regions, regions of microarc (III), and arc discharges (IV).

Changes in the oxide coating mass or thickness with increasing processing time are used in most works $[30,31]$ to describe the kinetic regularities of PEO. In our opinion, this is a reliable characteristic of the technological process for pure aluminum treatment. But, considering the multicomponent composition of the alloys, the unequal electrical conductivity of alloying metal oxides that complicates the processing and significantly changes the shape of the operating voltage chronogram, we propose to analyze the change in the voltage function [26] in total and differential form. This unconventional approach is quite informative $[32,33]$.

The change in voltage with increasing PEO time (function $U-t$ ) allows us to get a general idea of the total process and the stages of the process. Differentiation of the $U-t$ dependence in coordinates $d U / d t-U$ makes it possible to establish a transition between the stages, in particular, both the sparking initiation and sparking voltage.

The objective of present work is to study the features of plasma electrolytic oxidizing of aluminum alloys in electrolytes to obtain manganese- and cobalt-containing composites. 
To achieve the goal, it is necessary to solve the following tasks:

(i) To research the specific features of the aluminum alloys $\mathrm{PEO}$ in $\mathrm{KOH}$ and $\mathrm{K}_{2} \mathrm{PO}_{4}$-based alkaline electrolytes with the formation of manganese- and cobalt-containing composites. The analysis is based on the study of voltage changes during PEO.

(ii) To study the composition and morphology of synthesized composites.

(iii) Determine the phase composition and corrosion resistance of the obtained oxide systems.

\section{Materials and Methods}

3.1. Materials. The specimens of commercial aluminum alloys whose composition is given in Table 2 were used for the investigation.

The oxidizing was carried out in the $\mathrm{KOH}-$ or $\mathrm{K}_{4} \mathrm{P}_{2} \mathrm{O}_{7^{-}}$ based electrolyte solutions and also with the addition of $\mathrm{KMnO}_{4}$ and $\mathrm{CoSO}_{4}$, accordingly. The concentrations of electrolyte components are given in Table 3.

Analytical reagents and distilled water were used for the preparation of working solutions.

To form the coatings, the surface of specimens was subjected to mechanical treatment (grinding) followed by degreasing, water flushing, and drying at a temperature of $30^{\circ} \mathrm{C}$.

3.2. Coating Forming Method. The PEO was carried out in the galvanostatic mode. To form the coatings, the laboratory unit was used that included the stabilized industrial d.c. source B5-50 (manufactured in Ukraine) and the electrolytic cell with the forced cooling and mixing of working electrolyte. To control the working parameters of PEO, we used ammeter and voltmeter. The electrolyte temperature was maintained in the range of 20 to $25^{\circ} \mathrm{C}$. The polarization current density was in the range of 5 to $20 \mathrm{~A} / \mathrm{dm}^{2}$, and the final oxidizing voltage varied in the range of 120 to $240 \mathrm{~V}$. PEO stages were controlled visually and taking down the instrument readings.

3.3. Methods of the Study. A surface scanning electron microscope ZEISS EVO 40XVP was used for specimen examination. Images of a surface were gained by means of recording secondary electrons (BSE) by scan of an electron stream on specimen's surface that allowed with high-resolving ability and good contrast range to explore topography of a surface. For processing images used software environment SmartSEM. Chemical composition of a surface explored using the analysis of a characteristic roentgen spectrum filed by means of energy-dispersive spectrometer INCA Energy 350. Stimulation of X-rays was carried out bombarding radiation of specimens by the bundle of electrons with energy $15 \mathrm{KeV}$.

In addition, the element composition of coatings was defined using the X-ray fluorescent method and portable all- purpose commercial X-ray spectrometer "SPRUT"; a relative standard deviation was in the range of $10^{-3}$ to $10^{-2}$.

The structure of the deposits was examined by X-ray diffraction analysis using a diffractometer DRON-2.0 in monochromatic Co-K $\alpha$ radiation $(\lambda=1.7902 \mathrm{~A})$. The phase identification was carried out by comparing the distance between the planes $(d, A)$ and the relative intensities of the experimental curve with the data of the electronic file system PCPDFWIN.

\section{Results and Discussion}

Aluminum and its alloys are irreversibly oxidized in alkaline solutions with the formation of aluminate ions $\mathrm{AlO}_{2}{ }^{-}$and hydroxo-complexes of a varied composition $\mathrm{Al}(\mathrm{OH})_{3}{ }^{3-x}$ to achieve the passivation potential at which a thin layer of the phase oxide $\mathrm{Al}_{2} \mathrm{O}_{3}$ starts to form. At high voltages, a thick anode film [33] is formed on the surface.

\subsection{Plasma Electrolytic Coatings Obtained in KOH-Based} Electrolytes. The chronogram of voltage (Figure 1(a), dependence 1) of the aluminum PEO processing in a $\mathrm{KOH}$ solution $(\mathrm{pH}>12.0)$ at low current densities $\left(5.0 \mathrm{~A} / \mathrm{dm}^{2}\right)$ has a slight slope, and the differential dependence $d U / d t-U$ (Figure 1(b), dependence 1) is monotonically decreasing. Operating voltage does not exceed $70 \mathrm{~V}$ over the entire period of oxidizing. This indicates almost the same rates of formation and dissolution of phase oxide films, as a result of which conditions for the sparking initiation are not created. It prevents us from the realization of the treatment process in the PEO mode.

As the current density is increased, the dependences are changed; the voltage buildup rate increases in time (Figure 1(a), the dependences 2,3), and the peaks appear on the differential dependence $d U / d t-U$. An increase in $d U / d t$ is observed in the voltage range of 160 to $215 \mathrm{~V}$ (Figure 1(a), the dependences 2,3). Peaks on the differential dependence appear at $U_{\max }=200-215 \mathrm{~V}$, and in this case, a maximum becomes more explicit with the buildup in the polarization current. Obviously, at a higher current density, the rate of the solid oxide phase growth exceeds its dissolution rate. Thus, conditions are created for the breakdown of the phase oxide and the sparking initiation and then the transition of the process to the microarc mode.

The behavior of aluminum and its alloys in alkaline solutions that contain manganate(VII) ions differs from that of the processes in $\mathrm{KOH}$ solutions. Therefore, the addition of permanganate ions to the electrolyte considerably changes the differential dependence $d U / d t$ vs operating voltage (Figure 2).

The voltage change rate is increased in comparison with that of $\mathrm{KOH}$ solution and this change becomes stronger with an increase in the applied current density. A peak of the dependence becomes more explicit already at the voltages of 80 to $95 \mathrm{~V}$. The peak on the dependence (the maximum rate of voltage rise) corresponds to the sparking voltage. The sharp decrease in the $d U / d t$ is associated with the transition of the process to the sparking mode. Stabilization of the 
TABLE 2: The composition of aluminum alloys*, wt.\%.

\begin{tabular}{lccccccccc}
\hline Alloy grade & $\mathrm{Al}$ & $\mathrm{Cu}$ & $\mathrm{Mg}$ & $\mathrm{Mn}$ & $\mathrm{Fe}$ & $\mathrm{Si}$ & $\mathrm{Zn}$ & $\mathrm{Ti}$ & Other \\
\hline A1050 & Min 99.5 & To 0.05 & To 0.05 & To 0.05 & To 0.4 & To 0.25 & To 0.07 & To 0.05 & To 0.03 \\
A2024 & $90.9-94.7$ & $3.8-4.9$ & $1.2-1.8$ & $0.3-0.9$ & $\leq 0.5$ & $\leq 0.5$ & $\leq 0.3$ & $\leq 0.1$ & Ni $\leq 0.1$ \\
A3003 & $96.35-99.0$ & $\leq 0.2$ & $\leq 0.5$ & $1.0-1.6$ & $\leq 0.7$ & $\leq 0.6$ & $\leq 0.1$ & - & - \\
AlSi12CuNiMg & $79.5-85.55$ & $1.5-3.0$ & $0.8-1.3$ & $0.3-0.6$ & $\leq 0.8$ & $11.0-13.0$ & $\leq 0.5$ & $\leq 0.1$ & Ni $0.8-1.3 ; \mathrm{Pb} \leq 0.1 ; \mathrm{Sn} \leq 0.02 ; \mathrm{Cr} \leq 0.2$ \\
\hline
\end{tabular}

${ }^{*} \mathrm{Al}$, base of alloy; $\mathrm{Al}$ content is given approximately.

TABLE 3: Concentrations of electrolyte components.

\begin{tabular}{lcc}
\hline Electrolyte & Components & Concentrations $\left(\mathrm{mol} / \mathrm{dm}^{3}\right)$ \\
\hline \multirow{3}{*}{$\mathrm{KOH}$-based } & $\mathrm{KOH}$ & 0.01 \\
& $\mathrm{KOH}$ & 0.01 \\
& $\mathrm{KMnO}_{4}$ & $0.005 ; 0.05$ \\
$\mathrm{~K}_{4} \mathrm{P}_{2} \mathrm{O}_{7}$-based & $\mathrm{K}_{4} \mathrm{P}_{2} \mathrm{O}_{7}$ & $0.1 ; 1.0$ \\
& $\mathrm{CoSO}_{4}$ & 0.4 \\
& & $0.05 ; 0.1 ; 0.2$ \\
\hline
\end{tabular}
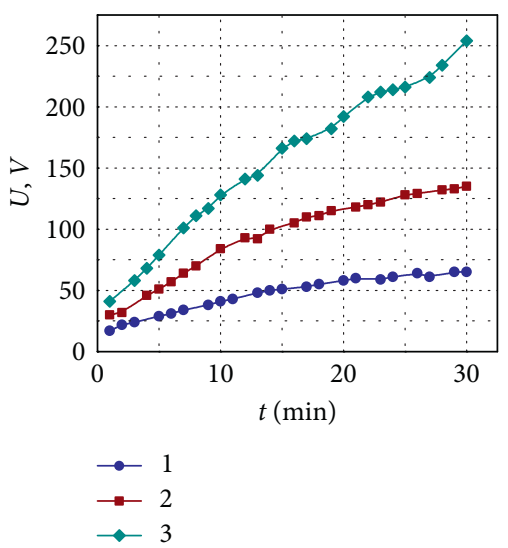

(a)

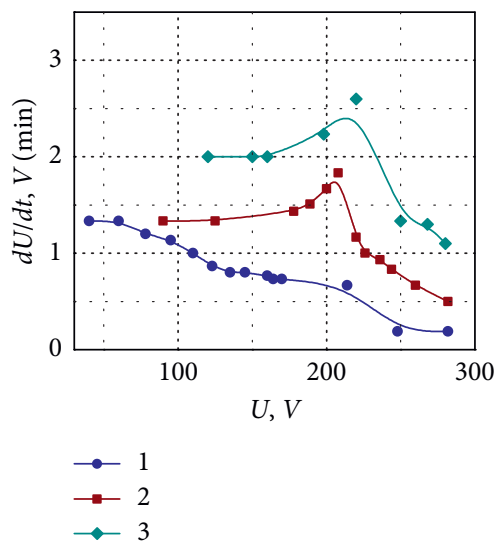

(b)

FIGURE 1: Voltage chronograms (a) and the rate of voltage change (b) at aluminum A1050 treatment in solution $0.01 \mathrm{~mol} / \mathrm{dm}^{3} \mathrm{KOH}$ at current density, $\mathrm{A} / \mathrm{dm}^{2}: 1-5.0 ; 2-10.0 ; 3-20.0$.

operating voltage $(d U / d t \longrightarrow 0)$ is observed during oxidizing in the microarc mode.

The sparking voltage and operating one in alkali permanganate electrolytes turns out to be lower than that of pure alkaline solution. It is explained by the fact that only

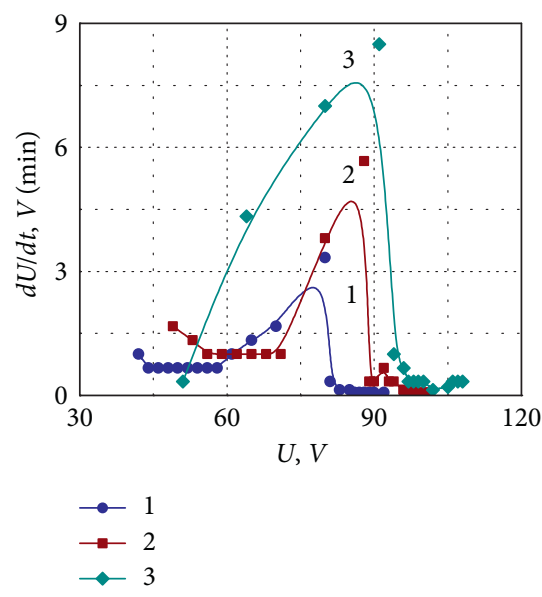

FIgURe 2: The rate of voltage change during PEO of aluminum A1050 in solution of $0.01 \mathrm{~mol} / \mathrm{dm}^{3} \mathrm{KOH}+0.05 \mathrm{~mol} / \mathrm{dm}^{3} \mathrm{KMnO}_{4}$ at current density, $\mathrm{A} / \mathrm{dm}^{2}$. 1: 5.0; 2: 10.0, 3: 20.0 .

aluminum oxide is formed in the alkali, and in the presence of permanganate, manganese oxides are incorporated into the $\mathrm{Al}_{2} \mathrm{O}_{3}$ matrix. The specific electric resistance of $\mathrm{Al}_{2} \mathrm{O}_{3}$ is several orders of magnitude higher than that of $\mathrm{MnO}_{\mathrm{x}}$, especially than $x \approx 2$; hence, the voltage decreases if mixed oxide coating forms.

The observed patterns agree with the mechanism of the coating formation in alkaline solutions suggested in [29]. It is shown the current is mainly consumed for the aluminum oxidizing, and the manganese oxides are formed in thermochemical and chemical reactions:

$$
\begin{aligned}
& 2 \mathrm{MnO}_{4}^{-} \longrightarrow \mathrm{MnO}_{4}^{2-}+\mathrm{MnO}_{2}+\mathrm{O}_{2} \\
& 3 \mathrm{MnO}_{4}^{2-}+2 \mathrm{H}_{2} \mathrm{O} \longrightarrow 2 \mathrm{MnO}_{4}^{-}+\mathrm{MnO}_{2}+4 \mathrm{OH}^{-} \\
& \mathrm{MnO}_{2} \stackrel{900 \mathrm{~K}}{\longrightarrow} \mathrm{Mn}_{2} \mathrm{O}_{3} \stackrel{1300 \mathrm{~K}}{\longrightarrow} \mathrm{Mn}_{3} \mathrm{O}_{4}
\end{aligned}
$$

occurring in the zones of spark and microarc discharges.

The oxidizing of aluminum alloys has its own specific features related to availability of alloying components and intermetallic compounds. First of all, PEO of aluminum alloys cannot be carried out in pure alkali solutions. The process proceeds with the formation of anodic oxide films, and the potentials of breakdown and sparking are not achieved.

The addition of $\mathrm{KMnO}_{4}$ to electrolyte leads to oxidizing of alloying components and promotes the transition of anodic oxidizing process into spark and microarc modes. Thus, the formation of oxide coatings doped with manganese on aluminum alloys is possible (Figure 3). 


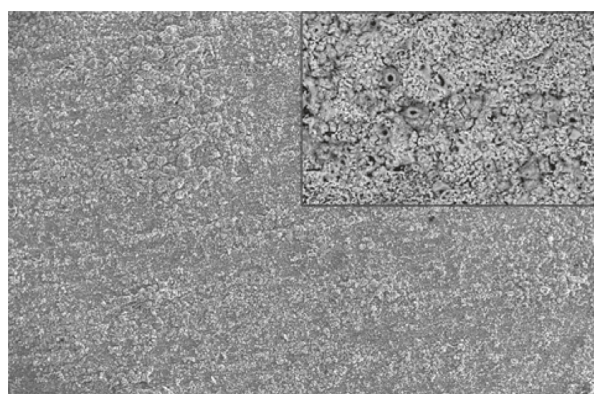

(a)

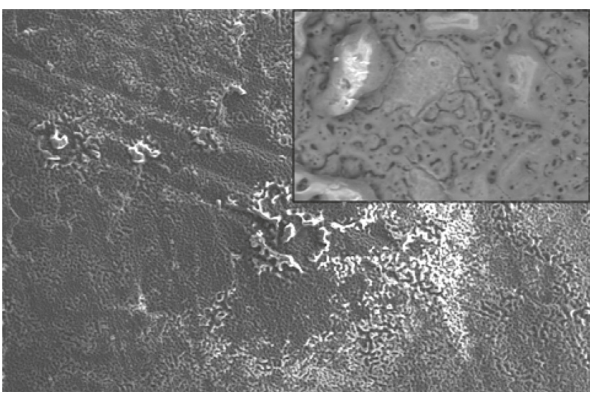

(b)

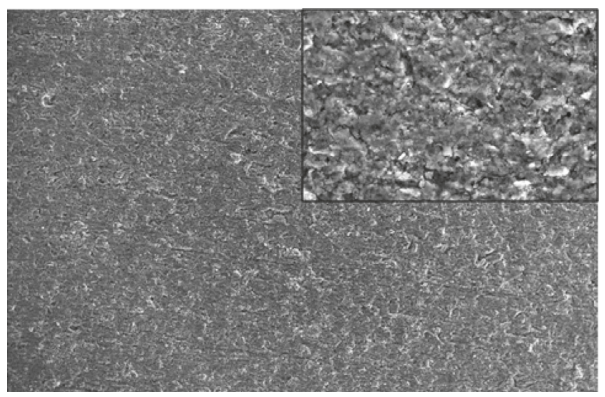

(c)

FIgure 3: Surface morphology of $\mathrm{Al} \mid \mathrm{Al}_{2} \mathrm{O}_{3}, \mathrm{MnO}_{\mathrm{x}}$ coatings on aluminum alloys: (a) A1050; (b) A2024; (c) A3003.

It should be noted that at low current densities $(i \leq 10 \mathrm{~A} /$ $\mathrm{dm}^{2}$ ), sparking is almost absent, the thickness of the forming coating varies slowly, and the manganese content in the surface layer is insignificant. To obtain coatings enriched with manganese, it is advisable to maintain the oxidizing current density at $15-20 \mathrm{~A} / \mathrm{dm}^{2}$.

The PEO of highly siliceous alloy AlSi12CuNiMg also has its own specific features and distinctions. The alloying components of alloy, especially $\mathrm{Si}$, destabilize the oxidizing process at the initial stage. Rather high current densities $\left(20 \mathrm{~A} / \mathrm{dm}^{2}\right)$ are required for their removal from the surface layer (surface homogenization) to reach an efficient conduction of the PEO process.

The shape of voltage chronograms (Figure 4(a)) shows a rapid increase in the voltage at the initial stage that corresponds to the formation of the phase aluminum oxide. In this case, the alloy heterogeneity conditions a certain difference in the sparking voltage and in the voltage change rate on the initial sections of voltage chronograms.

For one-stage PEO at a constant current density of $(20 \mathrm{~A} /$ $\mathrm{dm}^{2}$ ) (Figure 4(a), dependence 4), an oxidizing voltage is within $150 \mathrm{~V}$. The process rapidly goes into the mode of arc discharges, and it is accompanied by the coating damage. Therefore, it is expedient to oxidize the alloy in the two-stage mode: a higher current density at the first stage $i_{1}$ and subsequent decrease in current to $i_{2}$ after achieving a stable sparking.

It should be noted that an intensive coloring of the electrolyte complicates the visual control of accurate voltage indices at different PEO stages. Based on the analysis of the $d U / d t$ vs $U$ dependences (Figure 4(b)) and some on indirect features (the evaporation of electrolyte exposed to the action of micro discharges with a peculiar hissing sound), the

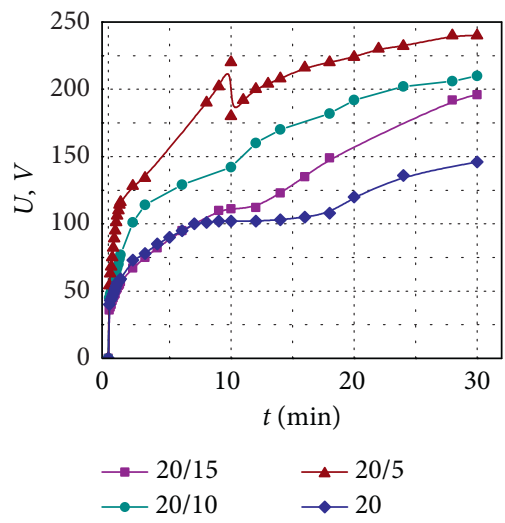

(a)

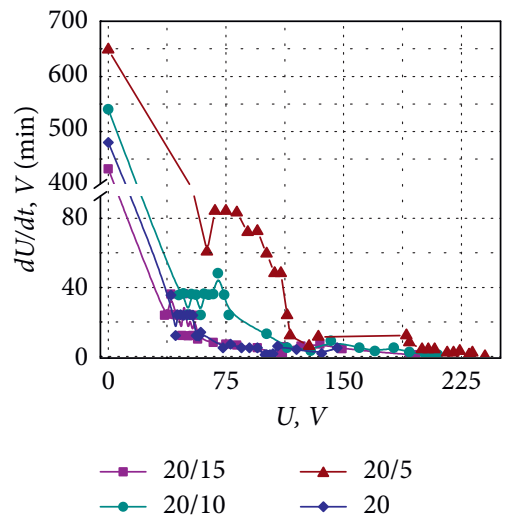

(b)

FIGURE 4: Voltage chronograms (a) and the rate of voltage change (b) at PEO treatment AlSi12CuNiMg in solution $0.01 \mathrm{~mol} / \mathrm{dm}^{3}$ $\mathrm{KOH}+0.005 \mathrm{~mol} / \mathrm{dm}^{3} \mathrm{KMnO}_{4}$ at current density $i_{1} / i_{2}, \mathrm{~A} / \mathrm{dm}^{2}$. 
sparking voltage $U_{\mathrm{s}}$ was established to be in the range of 125 to $135 \mathrm{~V}$.

We decreased the current density at the second stage to the range of 5 to $15 \mathrm{~A} / \mathrm{dm}^{2}$ after reaching stable sparking to maintain $\mathrm{PEO}$ in the microarc mode. The operating voltage of PEO reaches $230 \mathrm{~V}$ at $i 5.0 \mathrm{~A} / \mathrm{dm}^{2}$; however, the content of manganese in the oxide coating is insignificant that is probably related to the domination of the aluminum oxide formation. The current density at the second stage of 10 to $15 \mathrm{~A} / \mathrm{dm}^{2}$ provides the maintenance of the microarc mode during a long time. Lower operating voltage is associated with the inclusion of more conductive manganese oxides in the matrix of aluminum oxide, and the manganese content in the coatings reaches 36.0 at.\% (Figure 5).

The chemical analysis data show that after PEO treatment, the surface layer mainly contains manganese oxides, a small amount of aluminum oxide and silicon traces. The most important fact is that other alloying elements of the substrate were not detected in the formed coatings. It should be noted that manganese content in surface layers is slightly increased with the current density. The obtained data allow us to conclude that manganese oxides $\mathrm{MnO}_{\mathrm{x}}$ are embedded in the aluminum oxide matrix and form the external layer of coating. The above assumption is confirmed by the X-ray structural analysis of the surface oxide layer (Figure 6).

Figure 6 shows that PEO coatings formed in nonequilibrium conditions consist of manganese oxides of a different oxidation state, namely, $\mathrm{MnO}_{2}$ and $\mathrm{Mn}_{3} \mathrm{O}_{4}$. Besides, we see an amorphous halo at the angles of $2 \theta \sim 20^{\circ}$, and the last disappears after calcination of the coatings at a temperature of $600^{\circ} \mathrm{C}$. The portion of $\mathrm{Mn}_{3} \mathrm{O}_{4}$ oxides with higher thermal stability also increases after thermal treatment. These data correlate with the data obtained for PEO oxide systems on aluminum alloys and other valve metals $[29,34]$.

Analysis of the processes occurring during plasma electrolytic oxidizing of aluminum and its alloys in an alkaline electrolyte in the presence of potassium permanganate(VII) allows us to draw the following conclusions. For controlling the composition and morphology of oxide coatings, it is necessary to substantiate the choice of electrolyte composition (base component and additives), as well as to work out the current density. The electrolyte must ensure the oxidation of the alloying components from the surface layer and its homogenization to form a continuous matrix aluminum oxide. The current density of the PEO should ensure that the process proceeds in the sparkmicroarc mode.

To obtain the coatings on aluminum and its alloys with a high content of manganese, we recommend the electrolyte of the composition, $\mathrm{mol} / \mathrm{dm}^{3}: \mathrm{KOH}$ of $0.01 ; \mathrm{KMnO}_{4}$ of 0.005 to 0.05 , the polarization current density is 15 to $20 \mathrm{~A} / \mathrm{dm}^{2}$.

4.2. Plasma Electrolytic Oxide Coatings Obtained Using $\mathrm{K}_{4} \mathrm{P}_{2} \mathrm{O}_{7}$-Based Electrolytes. The mechanism of oxide systems formation on the aluminum and its alloys during the PEO in alkaline electrolytes containing the transition metals cations, for example cobalt, differs from that in permanganate

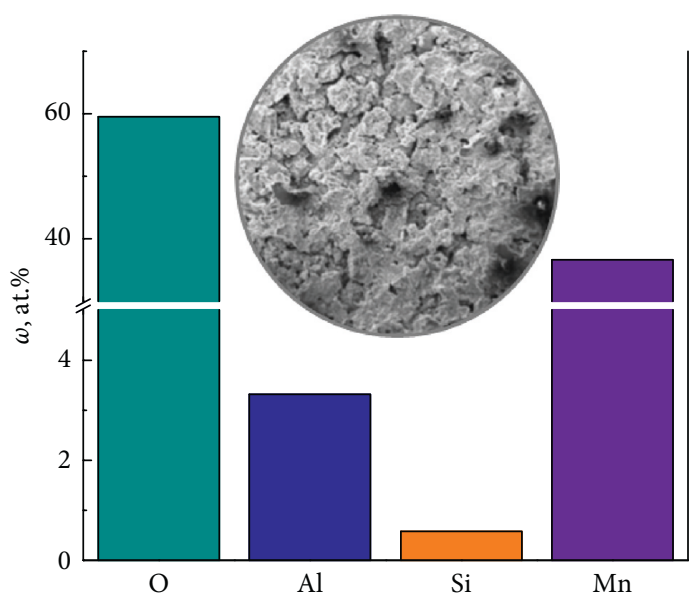

(a)

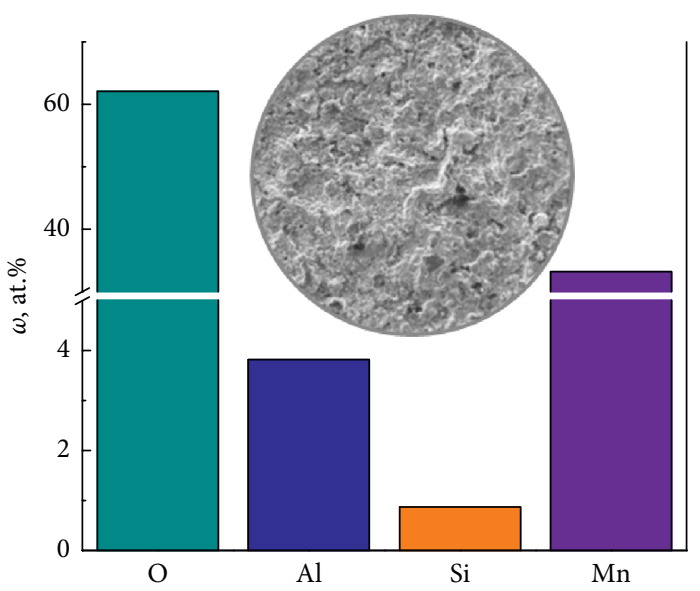

(b)

Figure 5: Surface morphology and composition of $\mathrm{Al} \mathrm{Al}_{2} \mathrm{O}_{3}$, $\mathrm{MnO}_{\mathrm{x}}$, coatings formed on AlSi12CuNiMg at current density $i_{2}$, $\mathrm{A} / \mathrm{dm}^{2}$. (a) 15.0 ; (b) 10.0 .

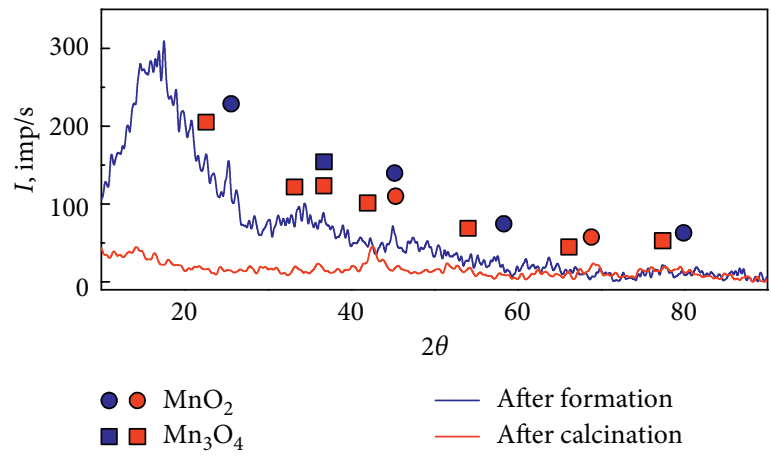

FIgURE 6: X-ray patterns of aluminum alloy with mixed oxide coating $\mathrm{Al}_{2} \mathrm{O}_{3}, \mathrm{MnO}_{\mathrm{x}}$, obtained in the electrolyte of $\mathrm{KOH}$ with additives $\mathrm{KMnO}_{4}$.

solutions. The reason for this is the ability of $\mathrm{Co}^{2+}$ for further oxidation, whereas in permanganates, manganese exhibits the maximum oxidation state. Sodium or potassium hydroxide solution is not suitable for oxidation, since cobalt(II) hydroxide precipitates. Therefore, alkaline electrolytes based 
on pyrophosphate, forming soluble complexes with the majority of transition metals, are used to form cobaltcontaining oxide coatings [23].

An analysis of voltage chronograms (Figure 7) is indicative of that the sparking voltage $U_{\mathrm{s}}$ for aluminum is varied in the range of 100 to $105 \mathrm{~V}$. From Figure 7, it is visible that the more the alloying additives an aluminum alloy contains, the lower the sparking voltage is, namely, for the A3003 alloy, it is varied in the range of 90 to $95 \mathrm{~V}$, for F2024, it is varied in the range of 80 to $85 \mathrm{~V}$, and for AlSi12CuNiMg, it is varied in the range of 95 to $105 \mathrm{~V}$. For all substrates the microarc mode is fixed in the voltage range of 150 to $200 \mathrm{~V}$. Therefore, the barrier layer will be formed faster on pure aluminum, while the attainment of the mode of microarc oxidizing takes much more time.

Such phenomenon can be explained by the availability of a great number of alloying components and intermetallic compounds in the surface layer of aluminum alloys. In this case, the portion of anodic current is consumed for partial oxidizing of alloy components and homogenization of the surface. In the long run, it results in the formation of the equipotential surface structure of treated materials.

As a result, the morphology of the processed materials' surface changes (Figure 8) (for example, alloy A2024): from the initial (a) to the areas of local anodic dissolution of alloying elements and a barrier aluminum oxide film formation (b, c) and the subsequent growth of a continuous oxide coating (d). In the latter case, the coatings have a microporous globular structure and the micropores are often interconnected with each other and form a tubular structure.

It can be argued that the three-dimensional cellular structure on the surface is formed due to the release of oxygen during the PEO process. High temperatures and pressures in the sparking zone and microarc discharges lead to an increase in the concentration of oxygen in the remelted oxides and closure of the pores. On the other hand, porosity contributes to the formation of a thicker oxide coating due to the facilitation of electrical discharge between the electrolyte and the substrate.

The chemical composition of untreated alloy and that treated in the pyrophosphate solution (Figure 9) is indicative of an efficient removal of alloying components and the surface homogenization with the formation of matrix aluminum oxide.

Thus, in the pyrophosphate solution, the content of the alloying components in the surface layer simultaneously decreases and phase aluminum oxide is formed. Homogenization of the surface is achieved by binding transition metals to the ligand pyrophosphate in soluble complexes.

The obtained data correlate with our results for titanium alloys [23] and with the data of other researchers [19]. It allows us to view the pyrophosphate solution as the basic one for transition metals (cobalt) incorporation into the composition of oxide coatings. It was previously established [18] that the partial oxidation reactions of aluminum, oxygen, and $\mathrm{Co}(\mathrm{II})$ can occur simultaneously in pyrophosphate electrolytes containing cobalt(II) during PEO. However, the mechanism and routes of reactions depend on electrolyte composition, current density, and operating voltage.

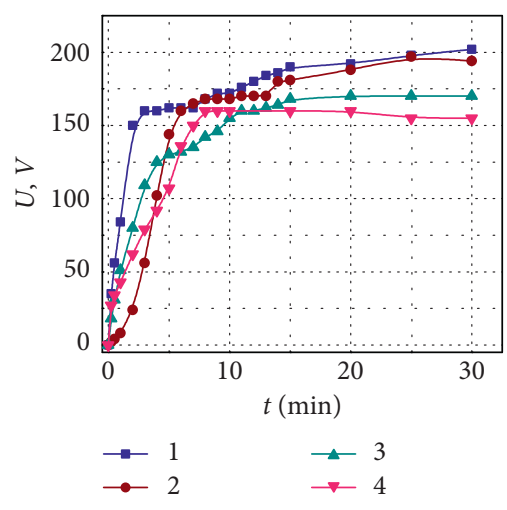

FIgURE 7: Voltage chronograms for PEO treatment of alloys. 1: A1050, 2: A3003, 3: A2024, 4: AlSi12CuNiMg; electrolyte $1 \mathrm{~mol} /$ $\mathrm{dm}^{3} \mathrm{~K}_{4} \mathrm{P}_{2} \mathrm{O}_{7}$, current density $5.0 \mathrm{~A} / \mathrm{dm}^{2}$.

The geometry of the initial sections of voltage chronograms at PEO treatment of pure aluminum in $1.0 \mathrm{~mol} / \mathrm{dm}^{3}$ $\mathrm{K}_{4} \mathrm{P}_{2} \mathrm{O}_{7}$ solution (Figure 10, Dependence 1) differs from the $U-t$ dependences in electrolytes with different cobalt concentrations (Figure 10, Dependences 2-4). The slope of the initial sections and the rate of voltage change decrease with an increase in the cobalt concentration in the electrolyte, and after 10-20 min of treatment a second wave appears on the dependences. The voltage of the first section is decreased with an increase in the concentration of $\mathrm{Co}^{2+}$ ions in the electrolyte while the parameters of the second section show no such concentration dependence. It can be stated that an increase in the cobalt(II) concentration in the pyrophosphate electrolyte leads to an increase in the time before the sparking onset.

The shape of the first wave of $U-t$ dependences is associated with two simultaneous electrochemical processes, in particular, the formation of aluminum phase oxide and the oxidizing of cobalt(II) progress on the same surface. The depletion of the presurface layer with $\mathrm{Co}^{2+}$ ions contributes to an increase in the portion of total current consumed for the $\mathrm{Al}_{2} \mathrm{O}_{3}$ formation, and it results in the voltage buildup and the transition of the PEO process into spark and microarc modes. As a result, the thermochemical reactions of the cobalt oxides transformation to the form with a higher specific electric resistance $\rho$ are initiated:

$$
\mathrm{CoO}_{2} \stackrel{-\mathrm{O}_{2}}{\longrightarrow} \mathrm{Co}_{2} \mathrm{O}_{3} \stackrel{-\mathrm{O}_{2}}{\longrightarrow} \mathrm{Co}_{3} \mathrm{O}_{4}, 2 \mathrm{Co}_{3} \mathrm{O}_{4} \longrightarrow 6 \mathrm{CoO}+\mathrm{O}_{2}
$$

and it results in a further voltage rising. For example, $\rho\left(\mathrm{CoO} \cdot \mathrm{Co}_{2} \mathrm{O}_{3}\right)=(1.1-1.6) \cdot 10^{4} \Omega \cdot \mathrm{cm}$, and $\rho(\mathrm{CoO})=10^{8} \Omega \cdot \mathrm{cm}$.

Considering the chemical composition, a peculiarity of aluminum alloys PEO in pyrophosphate electrolytes is that the anode dissolution of alloying components occurs at initial oxidizing stages. At this stage, oxyanions $\left(\mathrm{MO}_{\mathrm{y}}\right)^{\mathrm{z}}$ or stable complexes $\left[\mathrm{MP}_{2} \mathrm{O}_{7}\right]^{\mathrm{x}-}$ ( $\mathrm{M}$ is an alloying metal) can be formed. As a result, the homogenization of the surface occurs and the preconditions are created for the incorporation of dopant (cobalt) into the composition of growth aluminum oxide film. It should be noted that the 


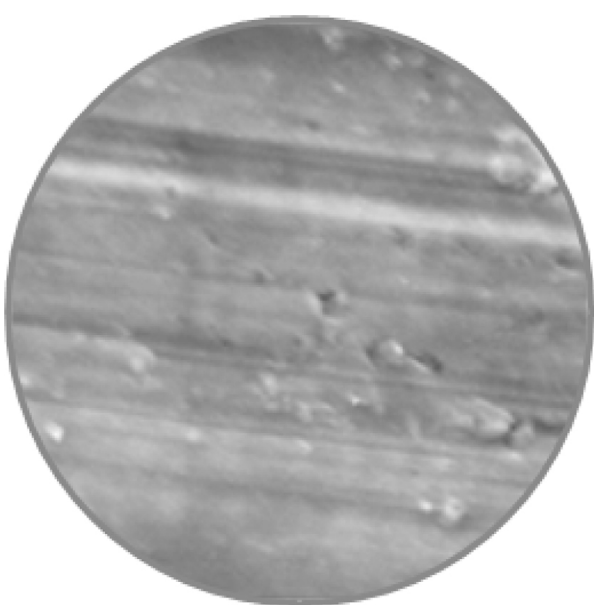

(a)

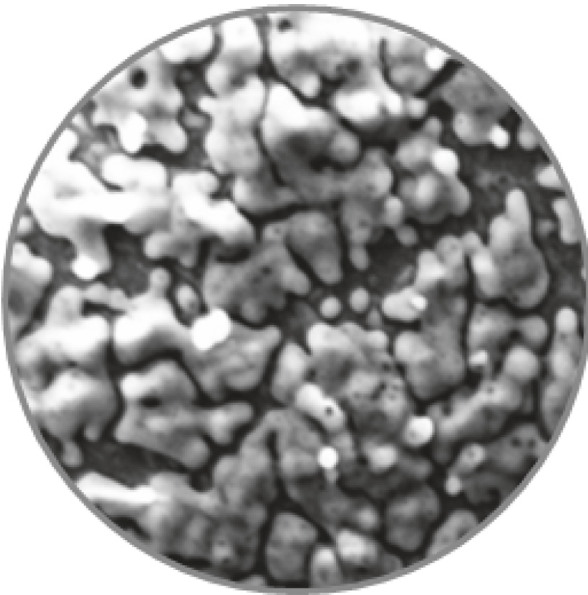

(c)

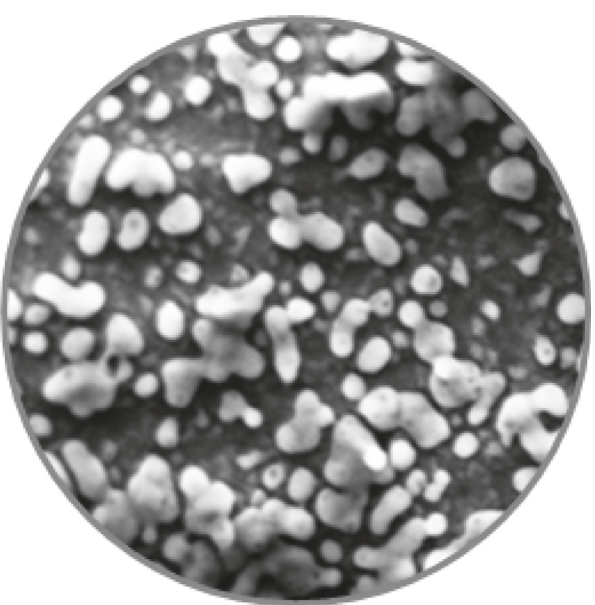

(b)

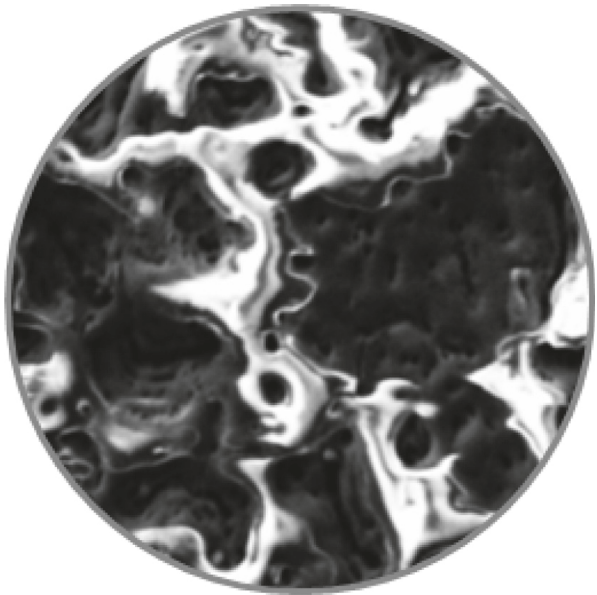

(d)

Figure 8: The surface morphology of oxide coatings formed on the alloy A2024 in a solution of $1.0 \mathrm{~mol} / \mathrm{dm}^{3} \mathrm{~K}_{4} \mathrm{P}_{2} \mathrm{O}_{7}$, during $\mathrm{PEO}$ at time intervals. (a) 5 minutes; (b) 7 minutes; (c) 10 minutes; (d) 30 minutes. Magnification $\times 1000$.

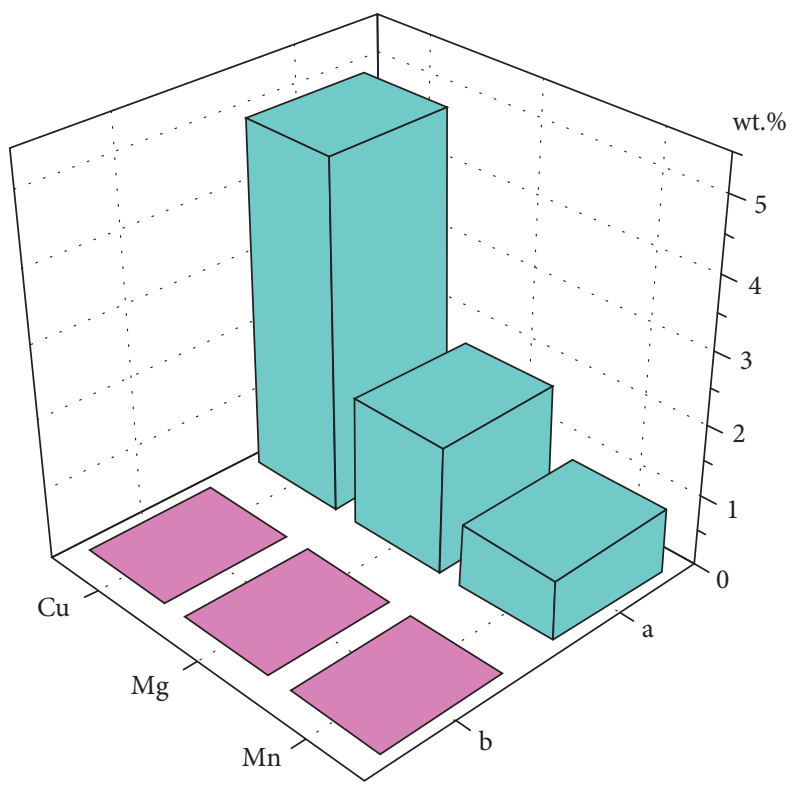

FIgURE 9: The content of the main alloying components in the surface layer of the alloy A2024: in the initial state (a) and after PEO in solution $1.0 \mathrm{~mol} / \mathrm{dm}^{3} \mathrm{~K}_{4} \mathrm{P}_{2} \mathrm{O}_{7}$ within 30 minutes (b). 


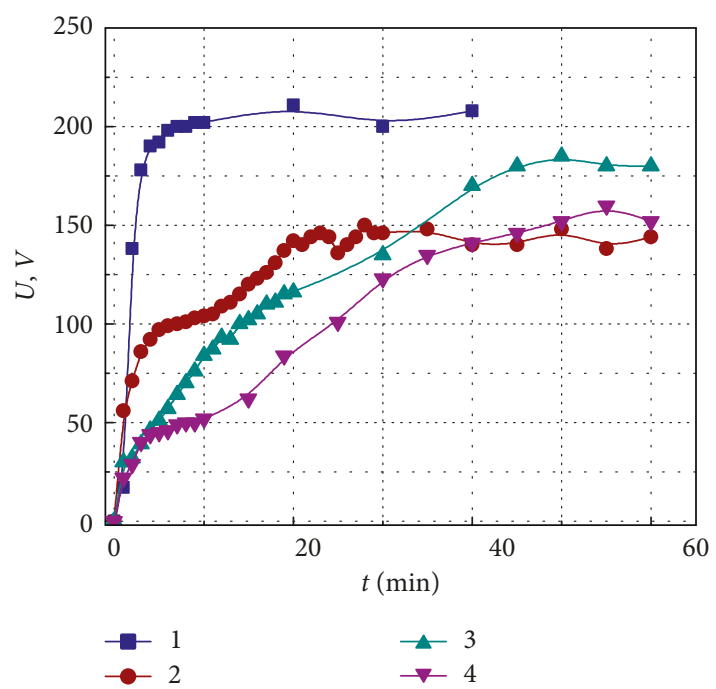

(a)

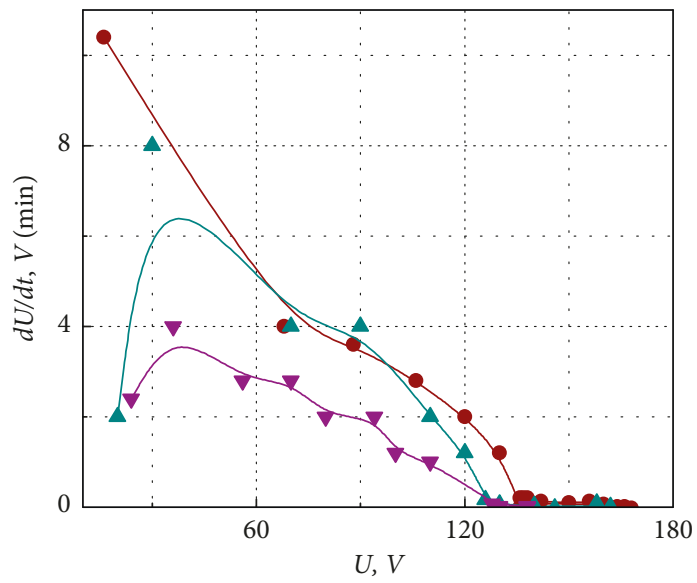

$-2$

$\rightarrow 3$

$\rightarrow 4$

(b)

Figure 10: Voltage chronograms (a) and the rate of voltage change (b) during PEO of aluminum A1050 in solutions $0.1 \mathrm{~mol} / \mathrm{dm}^{3} \mathrm{~K}_{4} \mathrm{P}_{2} \mathrm{O}_{7}(1)$ and when adding $\mathrm{CoSO}_{4}, \mathrm{~mol} / \mathrm{dm}^{3}: 0.025(2) ; 0.05(3) ; 0.1$ (4).

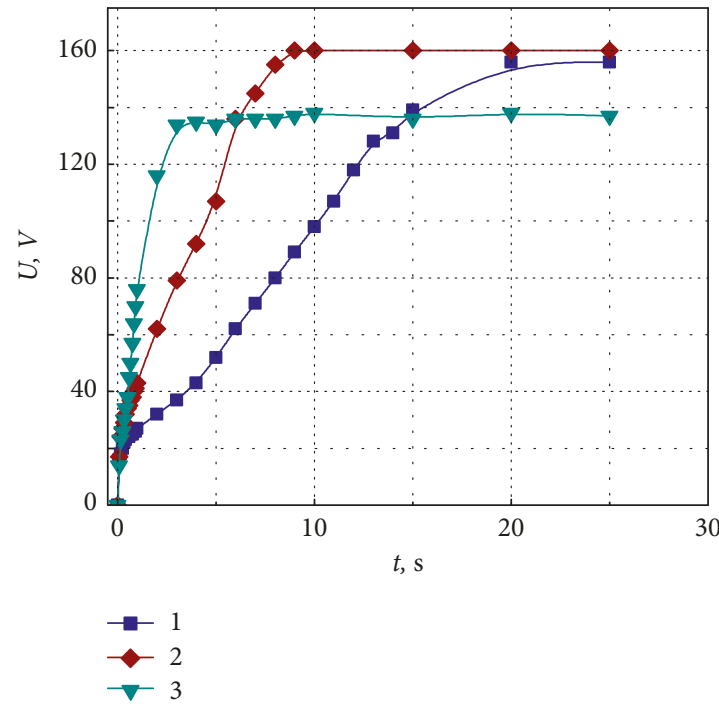

(a)

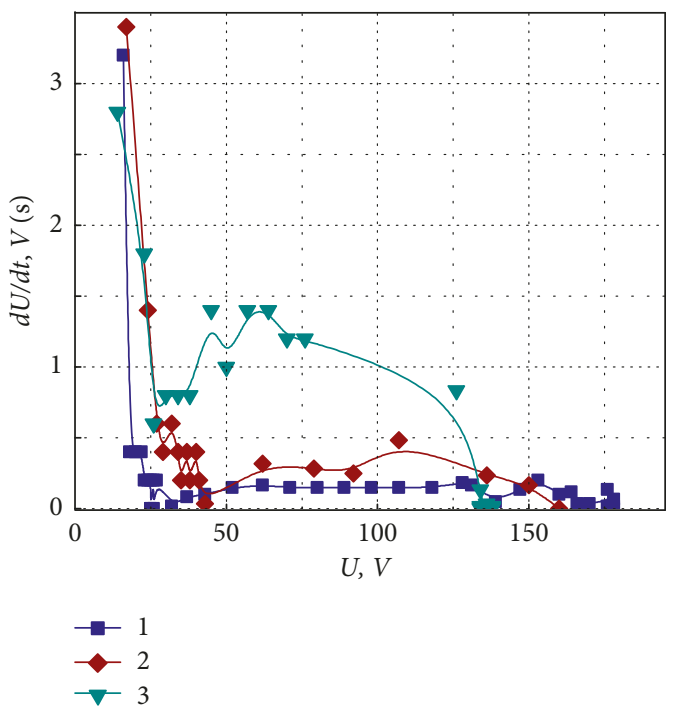

(b)

Figure 11: Voltage chronograms (a) and the rate of voltage change (b) during PEO of aluminum alloy in the electrolyte at a ratio of concentrations $\mathrm{K}_{4} \mathrm{P}_{2} \mathrm{O}_{7}$ and $\mathrm{CoSO}_{4}, \mathrm{~mol} / \mathrm{dm}^{3}$. 1: $8: 1\left(0.4 \mathrm{~K}_{4} \mathrm{P}_{2} \mathrm{O}_{7}, 0.05 \mathrm{CoSO}_{4}\right) ; 2: 4: 1\left(0.4 \mathrm{~K}_{4} \mathrm{P}_{2} \mathrm{O}_{7}, 0.1 \mathrm{CoSO}_{4}\right) ; 3: 3: 1\left(0.6 \mathrm{~K}_{4} \mathrm{P}_{2} \mathrm{O}_{7}, 0.2 \mathrm{CoSO}_{4}\right)$.

studied alloys are characterized by a considerable content of alloying components and their inhomogeneous distribution on the surface. Therefore, the PEO process will depend to a great extent on the electrolyte composition.

The efficiency of this process is reached due to an optimal ratio of ligand $\left(\mathrm{P}_{2} \mathrm{O}_{7}{ }^{4-}\right)$ and the doping component $\left(\mathrm{Co}^{2+}\right)$ in the electrolyte. A comparative analysis of voltage chronograms and the voltage change rate for the PEO of aluminum alloy (AK12M2MgN is taken as an example) is indicative of that the rate of cobalt-containing oxide film growth is increased with an increase in $\mathrm{CoSO}_{4}$ concentration and the sparking start time is shortened (Figure 11).
The sections of the dependences $U-t$ in the prespark domain are actually linear, and it is explained by the aluminum oxide film thickness growth and an increase of its resistance. The spark mode attainment time increases from 2 to 11 minutes if the $\mathrm{K}_{4} \mathrm{P}_{2} \mathrm{O}_{7}: \mathrm{CoSO}_{4}$ ratio increases from $3: 1$ to $8: 1$. In this case, the sparking voltage is in the range of 115 to $120 \mathrm{~V}$, and the final forming voltage is in the range of 140 to $160 \mathrm{~V}$.

The formed oxide layers have a high adhesion to the base metal. A variation of the cobalt content in the solutions conditions a change in the morphology and composition of the surface layer that was formed by PEO (Figure 12). 


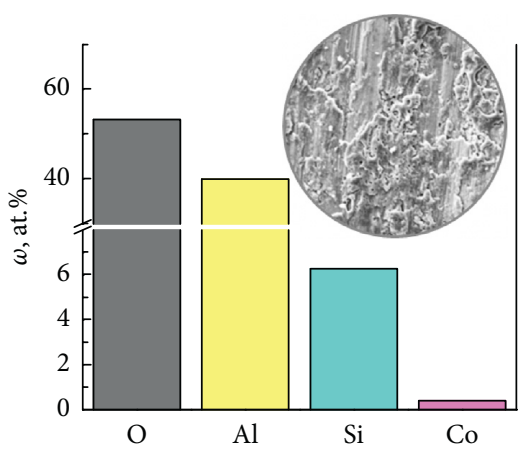

(a)

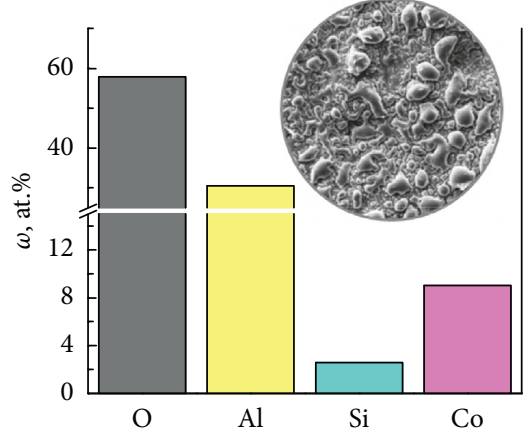

(b)

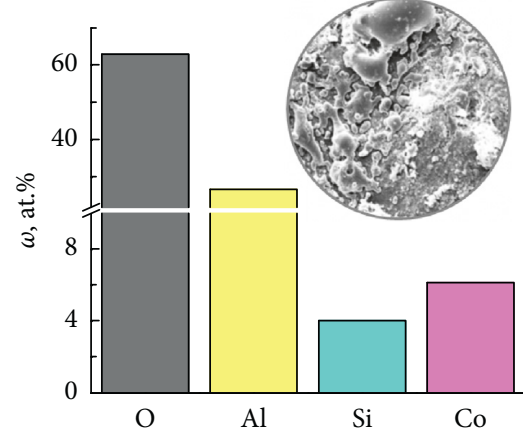

(c)

FIGURE 12: Surface morphology and composition of coatings formed on AlSi12CuNiMg in electrolyte of composition, mol/dm ${ }^{3}$ : (a) 0.4 $\mathrm{K}_{4} \mathrm{P}_{2} \mathrm{O}_{7}, 0.05 \mathrm{CoSO}_{4}$; (b) $0.4 \mathrm{~K}_{4} \mathrm{P}_{2} \mathrm{O}_{7}, 0.1 \mathrm{CoSO}_{4}$; (c) $0.6 \mathrm{~K}_{4} \mathrm{P}_{2} \mathrm{O}_{7}, 0.2 \mathrm{CoSO}_{4}$.

The incorporation of cobalt into the coating composition results in the formation of blue-violet spheroids on the surface. The morphology of oxide coatings is changed from rough with a low (up to 1 at.\%) cobalt content (Figure 12(a)) to globular (Figures 12(b) and 12(c)) as the dopant content reaches 9 at.\%. When the number of globular spheroids is rather high, these combine with each other to form highly developed mosaic structures that actually cover the entire specimen surface.

The obtained data are in full compliance with proposed mechanisms and enable the determination of a rational electrolyte composition to obtain the oxide coatings of a given composition and morphology.

Meaningful is the change in the content of alloying components, including $\mathrm{Si}$, in outer layers of AlSi12CuNiMg after treatment in the pyrophosphate electrolytes. Such minimization is reached when the PEO is conducted in the electrolyte of the composition $0.4 \mathrm{~mol} / \mathrm{dm}^{3} \mathrm{~K}_{4} \mathrm{P}_{2} \mathrm{O}_{7}+0.1 \mathrm{~mol} /$ $\mathrm{dm}^{3} \mathrm{CoSO}_{4}$.

A variation of the oxidizing current density allows us to obtain coatings with different cobalt content (Figure 13). An optimal current density for the formation of cobalt-enriched oxide coatings is $5.0 \mathrm{~A} / \mathrm{dm}^{2}$.

At the same time, in order to obtain PEO coatings with the cobalt content of more than 20 at.\%, we need to increase the formation time in the range of 30 to 60 minutes [18].

The incorporation of cobalt into the composition of formed oxide coatings when the PEO is conducted in cobaltpyrophosphate electrolytes is confirmed by the data of X-ray structural analysis (Figure 14).

Mixed cobalt oxide phases $\mathrm{Co}_{3} \mathrm{O}_{4}$ present in the coating. The line intensity on diffraction patterns reflects a quantitative composition of oxide systems. After oxide coating $\mathrm{Al}_{2} \mathrm{O}_{3}, \mathrm{CoO}_{\mathrm{x}}$ calcination at a temperature of $600^{\circ} \mathrm{C}$, the number and intensity of peaks corresponding to cobalt oxides increase.

Hence, the usage of alkaline solutions containing the transition metals salts allows us to efficiently PEO treatment of valve materials with the homogenization of the surface layer and the formation of oxide coatings with a considerable content of the dopants.

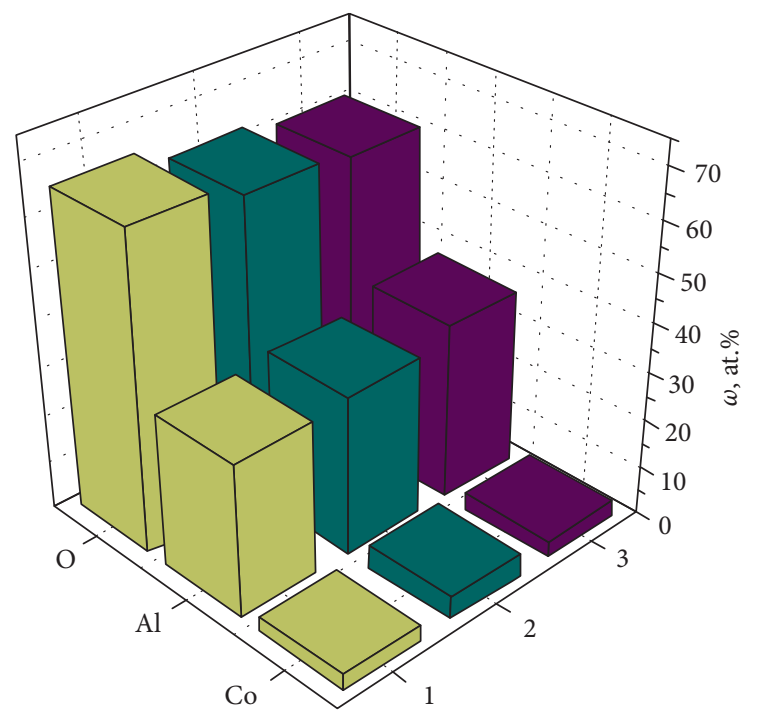

FIgure 13: The composition of the coatings $\mathrm{Al} \mid \mathrm{Al}_{2} \mathrm{O}_{3}, \mathrm{CoO}_{\mathrm{x}}$, formed in the electrolyte composition, $\mathrm{mol} / \mathrm{dm}^{3} 0.4 \mathrm{~K}_{4} \mathrm{P}_{2} \mathrm{O}_{7}, 0.1$ $\mathrm{CoSO}_{4}$ for $15 \mathrm{~min}$ at current density, A/dm². $1: 3.0 ; 2: 5.0 ; 3: 10.0$.

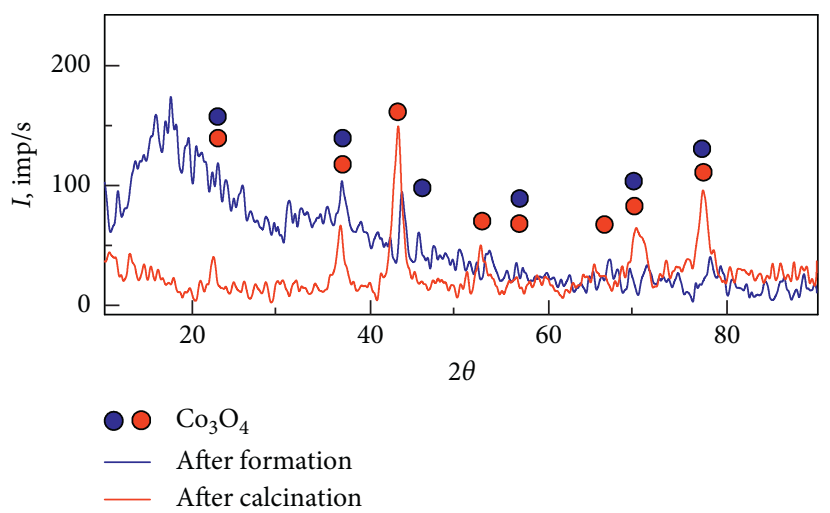

FIGURE 14: X-ray patterns of aluminum alloy with mixed oxide coating $\mathrm{Al}_{2} \mathrm{O}_{3}, \mathrm{CoO}_{\mathrm{x}}$, obtained in electrolyte of $\mathrm{K}_{4} \mathrm{P}_{2} \mathrm{O}_{7}$ with additives $\mathrm{CoSO}_{4}$.

The obtained results allow us to define optimal technological parameters for the formation of oxide coatings on aluminum alloys in alkaline electrolytes (Table 4). 
TABLE 4: Recommended technological parameters of aluminum alloys PEO treatment.

\begin{tabular}{|c|c|c|c|c|}
\hline \multicolumn{2}{|c|}{ Electrolyte } & \multirow{2}{*}{$\begin{array}{c}\text { Current } \\
\text { density } \\
\left(\mathrm{A} / \mathrm{dm}^{2}\right)\end{array}$} & \multicolumn{2}{|c|}{ Voltage (V) } \\
\hline Components & $\begin{array}{l}\text { Concentration } \\
\left(\mathrm{mol} / \mathrm{dm}^{3}\right)\end{array}$ & & Sparking & Maximum \\
\hline $\begin{array}{l}\mathrm{KOH} \\
\mathrm{KMnO}_{4}\end{array}$ & $\begin{array}{c}0.01-0.05 \\
0.005-0.05\end{array}$ & $15-20$ & $150-170$ & $220-240$ \\
\hline $\begin{array}{l}\mathrm{K}_{4} \mathrm{P}_{2} \mathrm{O}_{7} \\
\mathrm{CoSO}_{4}\end{array}$ & $\begin{array}{c}0.4-1.0 \\
0.05-0.1\end{array}$ & $3-5$ & $115-120$ & $140-160$ \\
\hline
\end{tabular}

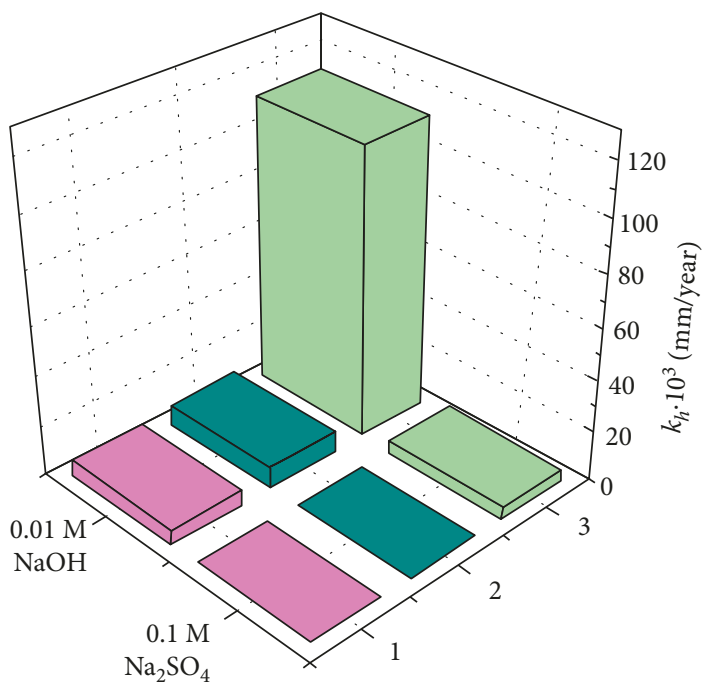

FIgURE 15: Deep $k_{\mathrm{h}}$ corrosion index of oxide coatings. 1: $\mathrm{Al}_{2} \mathrm{O}_{3}$, $\mathrm{CoO}_{\mathrm{x}} ; 2: \mathrm{Al}_{2} \mathrm{O}_{3}, \mathrm{MnO}_{\mathrm{x}}$; and 3: $\mathrm{Al}_{2} \mathrm{O}_{3}$, obtained in electrolyte based on $\mathrm{H}_{2} \mathrm{SO}_{4}$.

Specific features of the oxide coatings phase structure in combination with the developed surface, and a considerable content of the transition metal oxides is the precondition for the improvement of the functional properties of synthesized materials.

In particular, the PEO systems doped with manganese and cobalt show an increased corrosion resistance in different media (Figure 15).

Oxide coatings formed on pistons of ICE exhibit catalytic activity in redox reactions possessing with oxygen. $\mathrm{Al}_{2} \mathrm{O}_{3}, \mathrm{MnO}_{\mathrm{x}}$ system demonstrates the highest fuel economy of $3-4 \%$. When using a piston with $\mathrm{Al}_{2} \mathrm{O}_{3}, \mathrm{CoO}_{\mathrm{x}}$ coating, toxic gas emissions are reduced: $\mathrm{NO}_{\mathrm{x}}$ within $10 \%$ and $\mathrm{CO}$ $15-18 \%$ [34]. It allows us to view them as promising materials for air- and water-cleaning technologies and internal combustion engine waste gas purification systems $[35,36]$.

\section{Conclusions}

(1) It is shown that PEO of aluminum alloys in alkaline electrolytes based on $\mathrm{KOH}$ and $\mathrm{K}_{4} \mathrm{P}_{2} \mathrm{O}_{7}$ with $\mathrm{KMnO}_{4}$ and $\mathrm{CoSO}_{4}$ additives proceeds through the homogenization of the surface layer and the formation of oxide coatings doped with manganese and cobalt. The PEO technological parameters were established to be depended on the composition of the electrolyte used. The content of doping components is influenced by the concentration of the dopants in the solution and of the oxidizing current density.

(2) In the proposed modes, uniform oxide coatings $\mathrm{Al}_{2} \mathrm{O}_{3} \cdot \mathrm{MnO}_{\mathrm{x}}$ and $\mathrm{Al}_{2} \mathrm{O}_{3} \cdot \mathrm{CoO}_{\mathrm{y}}$ with manganese content up to 40 at. $\%$ and cobalt up to 25 at. $\%$ were formed onto the aluminum alloys substrates of various types. The incorporation of oxides of dopant metals in the composition of the surface layers is confirmed by the results of X-ray analysis.

(3) The obtained oxide systems are promising for use in air-cleaning and water purification systems, as well as for neutralizing exhaust gases of internal combustion engines.

\section{Data Availability}

The data used to support the findings of this study are available from the corresponding author upon request.

\section{Conflicts of Interest}

The authors certify that they have no conflicts of interest.

\section{Acknowledgments}

This research was conducted with the support of the Ministry of Education and Science of Ukraine within the confines of the project (registration number 0119U002568).

\section{References}

[1] H. Dong, Surface Engineering of Light Alloys: Aluminium, Magnesium and Titanium Alloys, Woodhead Publishing, Cambridge, UK, 2010.

[2] R. Lumley, Fundamentals of Aluminium Metallurgy, Woodhead Publishing, Cambridge, UK, 2011.

[3] G. E. Jai Poinern, N. Ali, and D. Fawcett, "Progress in nanoengineered anodic aluminum oxide membrane development," Materials, vol. 4, no. 3, pp. 487-526, 2011.

[4] V. S. Rudnev, I. V. Lukiyanchuk, M. S. Vasilyeva, M. A. Medkov, M. V. Adigamova, and V. I. Sergienko, "Aluminum- and titanium-supported plasma electrolytic multicomponent coatings with magnetic, catalytic, biocide or biocompatible properties," Surface and Coatings Technology, vol. 307, pp. 1219-1235, 2016.

[5] P. Gupta, G. Tenhundfeld, E. O. Daigle, and D. Ryabkov, "Electrolytic plasma technology: science and engineering-an overview," Surface and Coatings Technology, vol. 201, no. 21, pp. 8746-8760, 2007.

[6] F. C. Walsh, C. T. J. Low, R. J. K. Wood et al., "Plasma electrolytic oxidizing (PEO) for production of anodised coatings on lightweight metal ( $\mathrm{Al}, \mathrm{Mg}, \mathrm{Ti})$ alloys," Transactions of the IMF, vol. 87, no. 3, pp. 122-135, 2009.

[7] J. R. Davis, ASM Specialty Handbook: Aluminum and Aluminum Alloys, ASM International, Cleveland, OH, USA, 1993.

[8] V. S. Zolotorevsky, N. A. Belov, and M. V. Glazoff, Casting Aluminum Alloys, Elsiever Science, Oxford, UK, 2007.

[9] M. Ved, N. Sakhnenko, T. Bairachnaya, and N. Tkachenko, "Structure and properties of electrolytic cobalt-tungsten alloy coatings," Functional Materials, vol. 15, no. 4, pp. 613-617, 2008. 
[10] M. V. Ved', M. D. Sakhnenko, H. V. Karakurkchi, I. Y. Ermolenko, and L. P. Fomina, "Functional properties of Fe-Mo and Fe-Mo-W galvanic alloys," Materials Science, vol. 51, no. 5, pp. 701-710, 2016.

[11] A. B. Rogov, "Plasma electrolytic oxidation of A1050 aluminium alloy in homogeneous silicate-alkaline electrolytes with edta ${ }^{4-}$ complexes of $\mathrm{Fe}, \mathrm{Co}, \mathrm{Ni}, \mathrm{Cu}, \mathrm{La}$ and $\mathrm{Ba}$ under alternating polarization conditions," Materials Chemistry and Physics, vol. 167, pp. 136-144, 2015.

[12] A. M. Borisov, B. L. Krit, V. B. Lyudin, N. V. Morozova, I. V. Suminov, and A. V. Apelfeld, "Microarc oxidation in slurry electrolytes: a review," Surface Engineering and Applied Electrochemistry, vol. 52, no. 1, pp. 50-78, 2016.

[13] V. N. Malyshev and K. M. Zorin, "Features of microarc oxidation coatings formation technology in slurry electrolytes," Applied Surface Science, vol. 254, no. 5, pp. 1511-1516, 2007.

[14] F. Xu, Y. Xia, and G. Li, "The mechanism of PEO process on Al-Si alloys with the bulk primary silicon," Applied Surface Science, vol. 255, no. 23, pp. 9531-9538, 2009.

[15] P. Wang, J. P. Li, Y. C. Guo, Z. Yang, and J. L. Wang, "Ceramic coating formation on high Si containing Al alloy by PEO process," Surface Engineering, vol. 32, no. 6, pp. 428-434, 2016.

[16] L. Dai, W. Li, G. Zhang, N. Fu, and Q. Duan, "Anti-corrosion and wear properties of plasma electrolytic oxidation coating formed on high Si content $\mathrm{Al}$ alloy by sectionalized oxidation mode," IOP Conference Series: Materials Science and Engineering, vol. 167, article 012063, 2017.

[17] N. Y. Dudareva and M. M. Abramova, "The structure of plasma-electrolytic coating formed on $\mathrm{Al}-\mathrm{Si}$ alloys by the micro-arc oxidation method," Protection of Metals and Physical Chemistry of Surfaces, vol. 52, no. 1, pp. 128-132, 2016.

[18] M. V. Ved, N. D. Sakhnenko, A. V. Karakurkchi, and M. T. Yu, "Functional mixed cobalt and aluminum oxide coatings for environmental safety," Functional Materials, vol. 24, no. 2, pp. 005-310, 2017.

[19] D. L. Boguta, V. S. Rudnev, T. P. Yarovaya, T. A. Kaidalova, and P. S. Gordienko, "On composition of anodic-spark coatings formed on aluminum alloys in electrolytes with polyphosphate complexes of metals," Russian Journal of Applied Chemistry, vol. 75, no. 10, pp. 1605-1608, 2002.

[20] V. S. Rudnev, "Multiphase Anodic layers and prospects of their application," Protection of Metals, vol. 44, no. 3, pp. 263-272, 2008.

[21] I. S. Ponomarev, E. A. Krivonosova, and A. I. Gorchakov, "Investigation of discharge dynamics in microarc oxidation of D16 aluminium alloy," Welding International, vol. 30, no. 3, pp. 244-246, 2016.

[22] V. S. Egorkin, I. E. Vyaliy, S. L. Sinebryukhov, and S. V. Gnedenkov, "Composition, morphology and tribological properties of $\mathrm{PEO}$-coatings formed on an aluminum alloy D16 at different duty cycles of the polarizing signal," NonFerrous Metals, vol. 42, no. 1, pp. 12-16, 2017.

[23] N. D. Sakhnenko, M. V. Ved, and A. V. Karakurkchi, "Nanoscale oxide PEO coatings forming from diphosphate electrolytes," in Nanophysics, Nanomaterials, Interface Studies, and Applications. NANO 2016, O. Fesenko and L. Yatsenko, Eds., Springer Proceedings in Physics, Berlin, Germany, pp. 507-531, 2017.

[24] V. S. Rudnev, V. P. Morozova, T. A. Kaidalova, and P. M. Nedozorov, "Iron- and nickel-containing oxide- phosphate layers on aluminum and titanium," Russian Journal of Inorganic Chemistry, vol. 52, no. 9, pp. 1350-1354, 2007.

[25] S. V. Savushkina, L. E. Agureev, A. A. Ashmarin, E. A. Vysotina, A. V. Apelfeld, and K. A. Anikin, "The study of PEO coated zirconium doped aluminum composites," Journal of Physics: Conference Series, vol. 1121, article 012027, 2018.

[26] N. D. Sakhnenko, M. V. Ved', and A. V. Karakurkchi, "Effect of doping metals on the structure of PEO coatings on titanium," International Journal of Chemical Engineering, vol. 2018, Article ID 4608485, 10 pages, 2018.

[27] R. O. Hussein, X. Nie, and D. O. Northwood, "An investigation of ceramic coating growth mechanisms in plasma electrolytic oxidation (PEO) processing," Electrochimica Acta, vol. 112, pp. 111-119, 2013.

[28] I. V. Lukiyanchuk, V. S. Rudnev, and L. M. Tyrina, "Plasma electrolytic oxide layers as promising systems for catalysis," Surface and Coatings Technology, vol. 307, pp. 1183-1193, 2016.

[29] N. Sakhnenko, M. Ved, A. Karakurkchi, and A. Galak, "A study of synthesis and properties of manganese-containing oxide coatings on alloy VT1-0," Eastern-European Journal of Enterprise Technologies, vol. 3, no. 5(81), p. 37, 2016.

[30] L. Rama krishna, A. Sudha Purnima, N. P. Wasekar, and G. Sundararajan, "Kinetics and properties of micro arc oxidation coatings deposited on commercial Al alloys," Metallurgical and Materials Transactions A, vol. 38, no. 2, pp. 370-378, 2007.

[31] E. Erfanifar, M. Aliofkhazraei, H. F. Nabavi, and A. S. Rouhaghdam, "Growth kinetics and morphology of microarc oxidation coating on titanium," Surface and Coatings Technology, vol. 315, pp. 567-576, 2017.

[32] V. S. Rudnev, P. S. Gordienko, A. G. Kurnosova, and T. I. Orlova, "Kinetics of the galvanostatic formation of sparkdischarge films on aluminum-alloys," Soviet Electrochemistry, vol. 26, no. 7, pp. 756-762, 1990.

[33] L. O. Snizhko, A. L. Yerokhin, A. Pilkington et al., "Anodic processes in plasma electrolytic oxidation of aluminium in alkaline solutions," Electrochimica Acta, vol. 49, no. 13, pp. 2085-2095, 2004.

[34] A. S. Ivanova, "Aluminum oxide and systems based on it: properties and applications," Kinetics and Catalysis, vol. 53, no. 4, pp. 425-439, 2012.

[35] I. V. Parsadanov, N. D. Sakhnenko, M. V Ved' et al., "Increasing the efficiency of intra-cylinder catalysis in diesel engines," Voprosy khimii i khimicheskoi tekhnologi, no. 6, pp. 75-81, 2017.

[36] A. Karakurkchi, M. Sakhnenko, M. Ved, A. Galak, and S. Petrukhin, "Application of oxide-metallic catalysts on valve metals for ecological catalysis," Eastern-European Journal of Enterprise Technologies, vol. 5, no. 10 (89), pp. 12-18, 2017. 


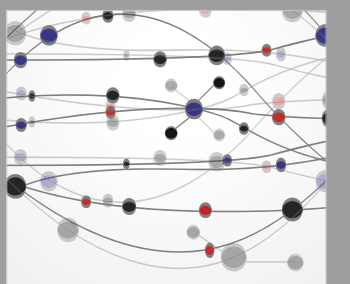

The Scientific World Journal
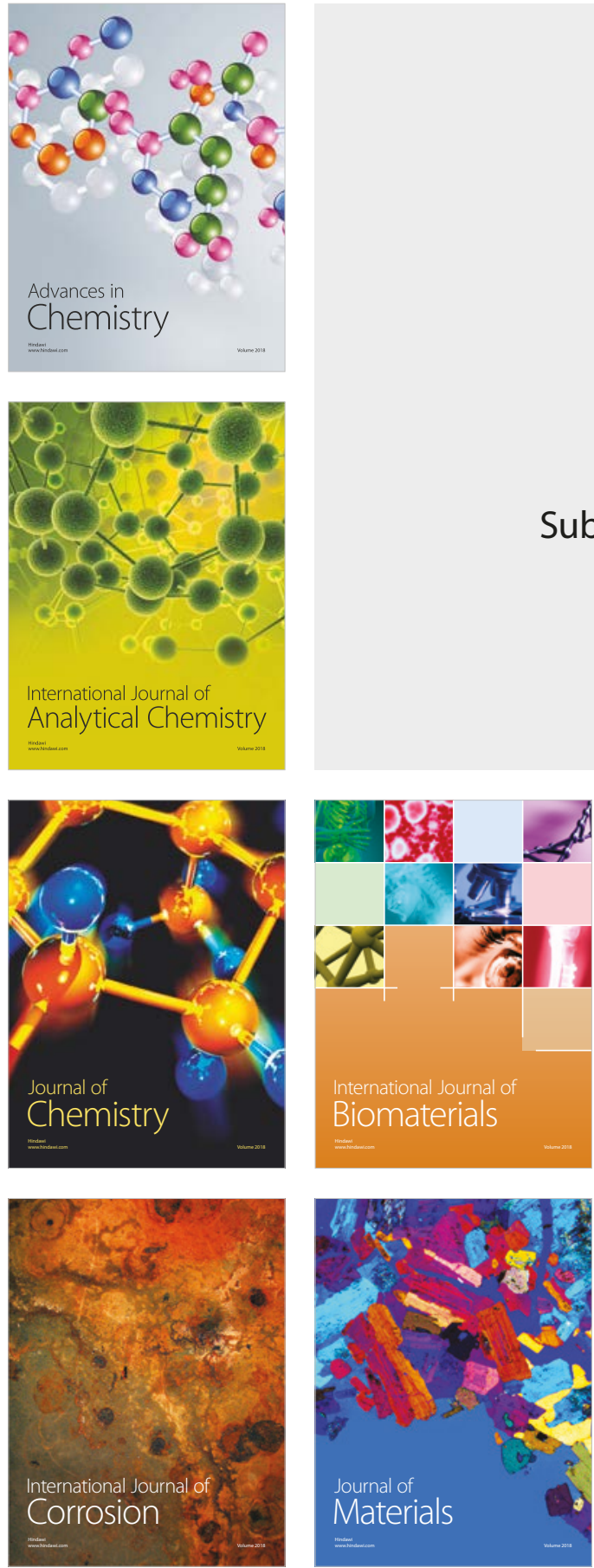

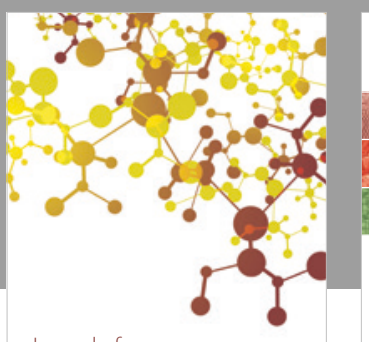

Journal of

Applied Chemistry
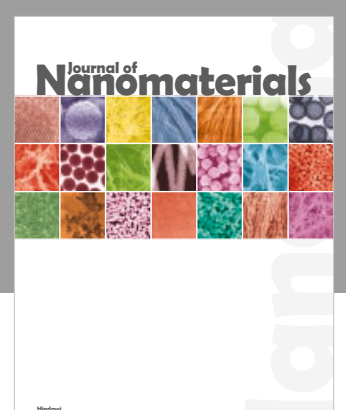

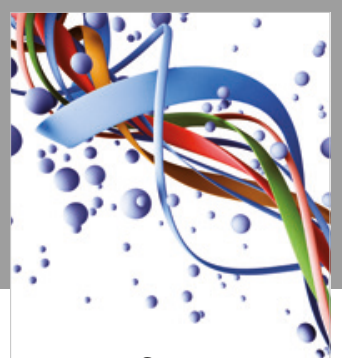

Scientifica

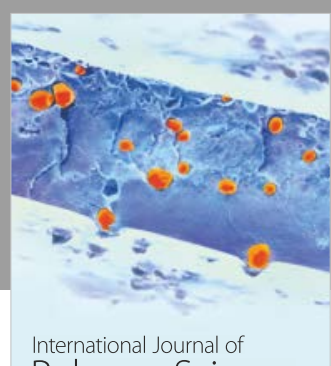

Polymer Science

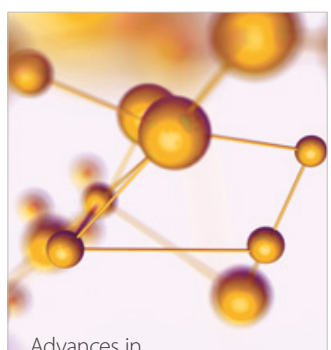

Physical Chemistry
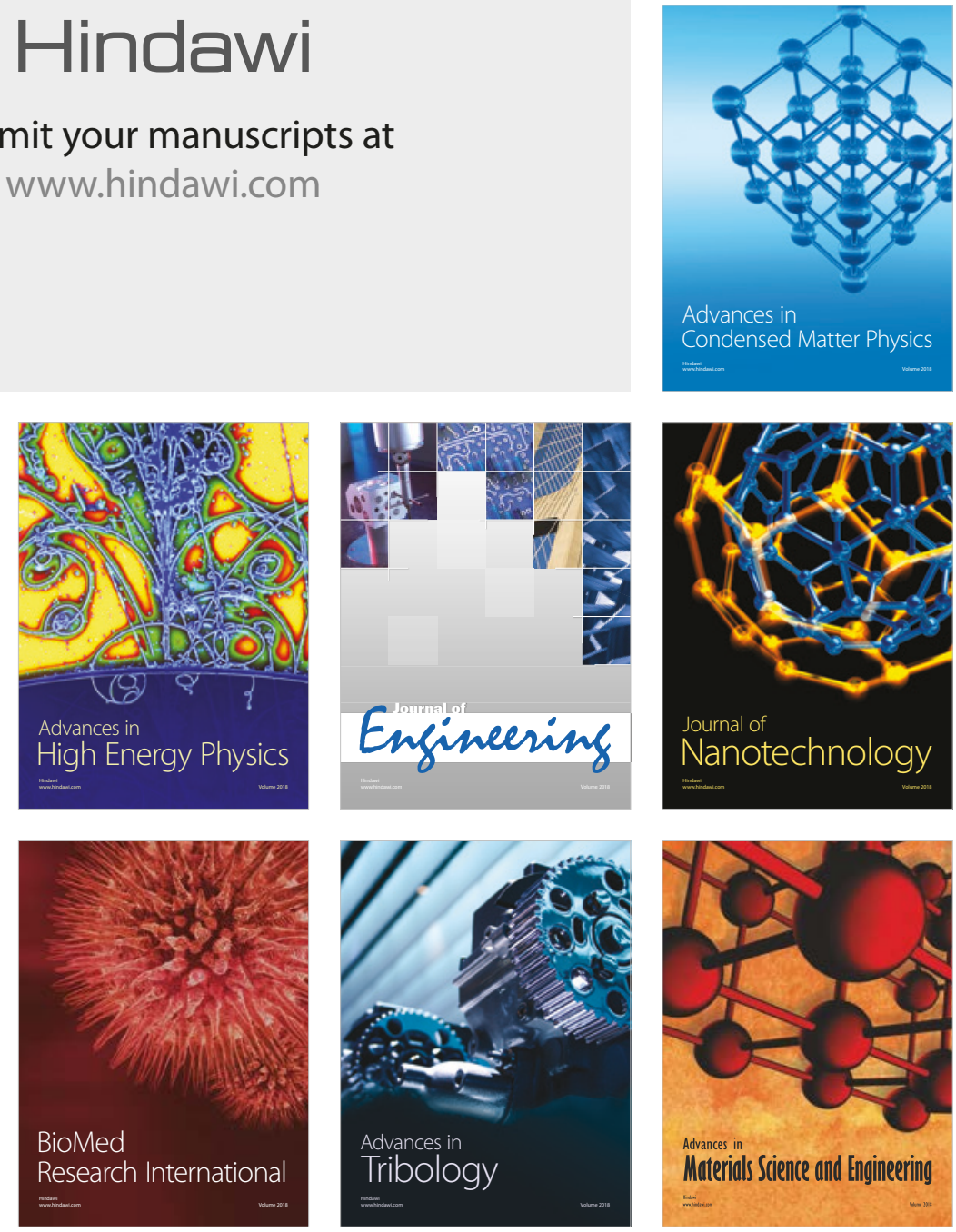